\title{
The globalized thought process in relation to natural resources
}

\author{
KELLY SWING \\ Tiputini Biodiversity Station, Universidad San Francisco de Quito, PO Box 17-1200-841, Quito, Ecuador \\ Manuscript received on February 24, 2019; accepted for publication on May 17, 2019
}

How to cite: SWING K. 2019. The globalized thought process in relation to natural resources. An Acad Bras Cienc 91: e20190236. DOI 10.1590/0001-3765201920190236.

\begin{abstract}
To understand the increasingly tenuous relationship between ourselves and the finite resource base upon which we depend for all sustenance, an exploration of recent history and basic human behavior is warranted. An attempt is made to shed light on how short-term economic demands have come to take priority over nearly all other long-term aspects of our existence. Without full recognition of our historical and cultural trajectories in relation to the modern mass mentality of materialism, consumerism and wealth, there is little possibility to develop or implement truly functional strategies that can be utilized indefinitely.
\end{abstract}

Key words: balance, equilibrium, logic, mentality, natural resources, thought process.

\section{INTRODUCTION}

Just like every individual of every other species, humans occupy space, use resources, produce waste and modify their surroundings. However, most species appear to be more restricted by niche space and competition than does Homo sapiens. The questions of "why?" and "how?" immediately arise in any conversation about our current status, the future of humankind and of our planet.

We depend almost entirely upon natural processes for the replenishment of vital resources such as potable water and fresh air. Beyond these indispensable provisions, by default and at no cost, environmental services have also always "taken care of" climate stability, liberation of oxygen, sequestration of carbon, the recycling of typical soil nutrients and countless other minerals, the physiology of primary productivity/ food availability, plant and animal reproduction/

E-mail: kswing@usfq.edu.ec

ORCID: http://orcid.org/0000-0002-7738-9769 replacement, pollination, equilibrium between predators, prey and pests/disease vectors as well as cultural, spiritual and recreational benefits. For better understanding of the overall context, humans must also recognize that absolutely every bit of raw materials we utilize for the fabrication of any tangible product of any kind depends upon nature, without exception.

Although our dependence on nature is complete and crucial - although this dependence includes everything that allows life as we know it - the masses are either complacently ignorant of this reality or consciously choose to ignore it altogether. In either case, we are exposing ourselves to tremendous hardship, physical and fiscal. This, in turn, perversely threatens our very existence at the expense of the masses and mostly in favor of the wealth and profit of a tiny proportion of the total human population.

As our numbers have grown exponentially, so have our demands on a plethora of specific resources as well as the global ecosystem. Concomitantly with 
our own increase, we have dramatically decreased, directly or indirectly, the populations of essentially every other large species of wild animal, terrestrial and aquatic, across the entire Earth to a fraction of what they were scant decades earlier. In the last century, we have come to impact negatively every square kilometer of our home planet.

Another automatic question arises in response to this situation: Is there any way to justify our extreme and obviously unsustainable exploitation of nature? Lastly, will we be able to overcome these challenges before being crushed by basic principles of physics and ecology?

"Understanding the laws of nature does not mean that we are immune to their operations." David Gerrold

\section{DISCUSSION}

"We use nature because it is valuable. We abuse nature because it is free." Barry Gardiner, Member of Parliament, United Kingdom

This statement may partially illuminate the overall phenomenon of human/nature interactions, but it does not explain much in relation to precisely how we arrived where we are today. A very superficial evaluation of Mr. Gardiner's comment would logically lead to the conclusion that both our use and abuse of nature are very nearly boundless. As "thinking beings", humans are capable of using past experiences to see into the future. This implies that we have long had the ability to understand and predict the outcomes of our actions. Consequently, the fact that we have overrun our resource bases time and time again can only be explained by complete and utter disregard combined with selfcentered and unfettered greed.

At this point, we are caught up in a vicious cycle. Our population grows so we subsequently consume more, which in turn, allows further growth - and so it goes, on and on. During the time when humans were not writing anything down, our numbers were minute and our impacts were undoubtedly insignificant beyond some tiny sporadically occupied patches. Eventually, as we came to be numerous and "civilized", in the last few thousand years, scattered city states appeared, but even in those population centers, environmental impacts likely only rarely extended beyond a radius of a few kilometers. Without motorized transportation, it would have been logistically impossible to produce and move sufficient foodstuffs and other products to huge cities like the ones we see in the modern world. What this means for the planet is that during the first few hundred thousand years "humans" were around, our significance to nature at the global scale was probably very close to nil. Small areas of intensive use surely occurred when the total human population was still limited to millions, but the phenomenon of worldwide impact was not a reality until much later, probably around the time of the Industrial Revolution. So, for far more than 4.5 billion years, the lack of human presence and abundance meant that nature ran its course constrained almost exclusively by the most basic principles of population ecology, with species either harvesting enough resources to survive and reproduce or they promptly went extinct. Their level of success and abundance was tied inexorably to specific activities and their efficiency to obtain necessities despite all challenges, including competition and risk of predation. We must assume that as species evolved, they were all limited in substantive ways by their resource bases. Another logical limitation was imposed through cropping off by predators. The idea of a "carrying capacity" was certainly applicable from the beginning of life for all species.

These concepts have also applied to humans during most of our brief history (Diamond 1997, 2005), but we must take into consideration that there has probably never existed a macroscopic species as opportunistically capable as humans ever before in any situation. We have the unusual talent to use 
nearly any material directly as a resource or to convert nearly anything into something that we can use. Our cooperative social behavior, in conjunction with exceptional intelligence and communication skills, has provided us with the impetus that has resulted in unrivaled dominance by our highly singular species. We began by having mostly physical impacts on the landscape; humankind is, above all, the greatest of all ecosystem engineers. We eventually came to have expansive chemical impacts as well. At present, we have structurally modified our surroundings across three-quarters of the Earth's surface to one degree or another. On the other hand, our chemical impacts reach every last square centimeter, from the most remote chunks of glacial ice in Antarctica to the deepest trenches of the ocean. Harvard Professor Emeritus E.O. Wilson (2016) has suggested that at least half the planet must be preserved in its natural state if civilizations have any realistic potential to persist indefinitely. On the balance sheet, therefore, we are currently at a tremendous deficit that can only be recovered through decisive actions and a drastic decrease in the human population. However, given our behavioral precedence, we can expect, at best, a lag time of decades before any meaningful turnaround may be made. Although we constantly repeat the old adage that, "those who do not learn from history are destined to repeat it", we must recognize that the greatest and most consistent lesson we have learned from history is that we learn nothing from history.

Some aspects of our chemical footprint are entirely intentional while others are "incidental". Broad applications of pesticides, herbicides, fungicides and fertilizers have planned results, but always involve a long list of side effects, some well documented and some yet undiscovered or intentionally undisclosed. In addition, the release into the environment of more than $80 \%$ of all sewage around the globe, from the human population as well as our livestock, presents a eutrophication pressure that simply cannot be absorbed by any ecosystem on the local scale. A dozen or so "dead zones" (massive volumes of sea water depleted of dissolved oxygen through organic/biological demand along with an array of toxins impossible to evaluate scientifically in their potential synergetic devastation) located at the mouths of major rivers downstream from population/agricultural/industrial centers (NOAA 2019) are testimony to our abuse in this regard.

Some portion of our kind, the most naïve perhaps, believe that somehow humans will be spared the consequences of ecological law. The precise mechanism is usually assigned to divine intervention, that a benevolent god will "fix" things before complete collapse (Weber 1905). Another position is that evolutionary forces will be able to miraculously accommodate humans, somehow fitting us into the earthly ecosystem in a sustainable way. Both scenarios depend upon unproven speculation. The former reflects blind faith on the part of the religious and the latter demands that the process of evolution would gain some capacity to predict the future and also, become goal-oriented. The scientific community would argue that neither is realistic and that humans will soon be confronting conditions that are literally existential at their root.

"I do not feel obliged to believe that the same God who has endowed us with sense, reason and intellect has intended us to forgo their use." Galileo Galilei

For some numerical context, let's consider where we stand in relation to the population explosion. Currently, there are nearly 8 billion people living on Earth. This number continues to grow and shows little indication of slowing. Projections for an eventual maximum lie between 9 and 12 billion by the end of the $21^{\text {st }}$ Century. Our population doubled in the last 50 years. That amounts to constantly adding the equivalent of a São Paulo or New York every month or so. Where indeed can we realistically expect the total to level 
off? All logic indicates that we must be approaching an asymptote. When we were approaching the onebillion mark, Thomas Malthus (1798) warned us of the potential to outstrip our resource base. Of the few people who heard his message, most responded by calling him a lunatic. Paul Ehrlich (1968) reiterated similar concerns as we were approaching 4 billion. Likewise, the masses ignored his warnings and we have gone on with "business as usual". Despite the validity of their logic, we have continued mocking them, tangibly demonstrating that we can continue to grow and not suffer a catastrophic crash. How is that possible? Were they simply wrong? A few explanations are in the offing. The first and easiest is that we have occupied more and more space with our crops and we have developed immense transportation networks to bring products from essentially anywhere to innumerable consumers, the global market. The second is that we have made agricultural practices more efficient by incorporating technological advances. Those historical personages may not have predicted a third explanation at the worldwide dimension - that we have expropriated the niche space of countless other organisms. We have done this to the tune of taking over about $90 \%$ of all mammalian biomass on the planet with ourselves and our livestock (BarOn et al. 2018). This same team estimated that poultry on farms now occupies about $70 \%$ of all avian biomass. These factors have allowed us to constantly raise the limits on how many of us can exist. Usually the zero-sum method of calculating balances is overly simplistic and should be avoided because winners and losers are unrealistically depicted as absolute. As an illustration, however, it does help to explain how we have increased our own carrying capacity at the expense of all others. Our insidious, and unconscious, method involves eliminating the vast majority of competing interests. This artificial raising of the bar for ourselves is not likely sustainable for much longer. It most certainly does not represent any semblance of ecological equilibrium. There is indeed madness to our method.

"We have a finite environment - the planet. Anyone who thinks that you can have infinite growth in a finite environment is either a madman or an economist." Sir David Attenborough

Recognizing that our sheer abundance is problematic hardly scrapes the surface of an underlying, much greater complication. Our behavior as a species continues to metamorphose. The masses have come to have very different ideas about the human condition and what is required to be able to categorize life as "dignified". Even language has become inadequate to describe our behavior and our interface with resources to the point of losing capacity to realistically analyze our personal situations. Connotations surrounding the meanings of "wants and needs" for example, are more confusing than previously. "Need", as a noun, is classically defined as "a lack of some requisite". Basic human needs are traditionally listed as "food, shelter and clothing". In contrast, "want" is defined as "a strong desire for something". Within the category of food, we find water. We all need water, without doubt, although some of us might want that water in a more luxurious form. - A vintage wine from a particular province perhaps? Most of us would say we need shoes, while some would want the most technologically-advanced sporting footwear or the costliest styles presented in Vogue. When we think about psychological aspects of our perceptions, the distinction between wants and needs may become especially nebulous. That does not relieve the necessity to recover some fundamental perspective here.

"There is sufficiency in the world for man's need but not for his greed." Mohandas K. Gandhi

For some context, the Mahatma made this comment most of a century ago - when there were only 2 billion human inhabitants of Earth, a quarter of today's population. 
For some insight into popular logic, it will be worthwhile to revisit some basic ecological tenets. The Principle of Competitive Exclusion (Gause 1934) essentially tells us that in nature, there are winners and there are losers; some species thrive and others meet their demise. As a corollary, we might interpret this to mean that our huge numbers represent a proxy measure of success. And that we are justified in pushing "lesser" beings off the playing field. Instead of lamenting the loss of species, shouldn't we be celebrating our victory, domination over all others? By having fewer competitors, we gain access to more resources for ourselves. Common sense conclusion: That leaves more stuff for us! Why would we stop now?

"In our attempt to make conservation simple, we have made it trivial." Aldo Leopold

While reading that last paragraph of overly simplistic "reasoning", many scientists would undoubtedly begin to balk due to a series of very nearly absurd examples of the continuum fallacy. While some extremely abundant organisms are indeed considered to be "successful", many uncommon organisms have been around for so many millennia that we certainly cannot discount their "success". Also, abundance and population growth without equilibrium guarantee complications. This mentality falls very close to the perceived strategy of cancer cell reproduction, which typically has a most destructive endpoint. Driving other species to extinction is exceptionally short-sighted in any logical argument as it eliminates the possibility of ever using them as resources. Because all life forms are interdependent at some level, the eradication of too many of them could very well provoke a change in conditions that allow us to survive on this third rock from the sun. If we were actually winning some competition for domination of the planet, we would have to consider several long-range factors, including those pointed out by Malthus (1798) two centuries ago and Ehrlich (1968) fifty years ago. So-called modern peoples have unleashed a wave of unsustainable death and destruction at the landscape scale during the last two centuries, but have the audacity to criticize ancestral/traditional cultures that they are the ones doing it all wrong.

Beyond our mere abundance, we must recognize several factors that have allowed us to dominate the planet, while making us particularly vulnerable to ourselves. These (including but not limited to boundless opportunism, extreme innovation, self-centered interests, unbridled consumerism) have led to a multitude of broad and deep impacts which we all know far too well. Topping that list are pollution, elimination of wilderness, mass extinction (Kolbert 2014), desertification and climate change. Some are huge; some are global, some are regional; some could easily be remedied; some will be impossible to overcome. Rachel Carson (1962) warned us over half a century ago precisely where this was headed, but society chose to ignore her message - that we were effectively silencing the symphony of nature by eliminating other species, literally destroying the planet.

Brazilian author Paulo Coelho later responded with some sobering words.

"How can we be so arrogant? The planet is, was, and always will be stronger than us. We can't destroy it; if we overstep the mark, the planet will simply erase us from its surface and carry on existing. Why don't we start talking about not letting the planet destroy us?"

Faced with all this, how do we, as the only thinking organisms on the planet, react? Given the potential costs, are we too comfortable with what we have become to actually do more than some symbolic acts? The primary motto for individuals from every rung of the societal ladder seems to be "Grab all you can". That, along with "dilution is the solution to pollution", may have once had some practicality with very low population densities, but these strategies probably lost all functionality/ sustainability with the Industrial Revolution. In 
combination with our numbers, our basic behavior is at the root of all our woes (Hardin 1968). We need conscious decisions founded in scientific evidence. The tradition of preaching to the ignorant has helped in the past and could produce some reasoned support if not hampered by the current wave of politically generated rejection of science sweeping some parts of the world. Corruption, selfinterests, social clout and economic inertia continue to complicate any logical progression toward rational resolution of the challenges humans face. Individual scientists, true experts, with sufficient experience and ample perspective, must actively speak out and be heard if we are to have any chance at overcoming the challenge of ourselves. Science has produced all the modern conveniences we have and can produce answers to other difficulties as well, but the masses must demonstrate willingness to change.

Most people understand, at least marginally, the inordinate amount of power fossil fuel industries exercise over huge budget and policy-making processes, but we should broaden our knowledge to take into consideration other examples of chemicals that also represent big business: pesticides, herbicides, fungicides and fertilizers. These all make large sums of money and facilitate the monopolizing of huge swathes of the landscape. Again, we are using every means possible to exclude all competitors. And, stereotypically, anyone or anything in the way is told that they must acquiesce for the greater good (Swing 2014, Swing et al. 2012). The same scenario applies equally for crude oil, natural gas, coal, iron ore, gold, copper, diamonds, soy, sugar cane, African (oil) palm, cattle ranching, and on and on and on.

City dwellers have reasonable sway over these kinds of operations in some places, but big business overwhelmingly tends to get its way in developing countries, especially in remote areas. In population centers, the concentration of voters tends to bring some balance to the exploitation of local resources, while those who live in low densities are generally relegated to the will of the almighty dollar. Specifically, indigenous peoples living traditional lives in ancestral territories, due to their relatively low numbers and societal rank, often have no real voice in what happens on their lands. In those situations, violation of the right to self-determination has too often become a malady of standard practice.

"Genocide, the physical extinction of a people is universally condemned, but ethnocide, the destruction of a people's way of life, is not only condoned, it is universally celebrated as part of a development strategy." Wade Davis

Despite the invaluable role that indigenous peoples play in the conservation of their traditional lands and a huge portion of biota (Alcorn 2010), they have mostly been treated as "complications" by invaders driving to gain access to wealth through the regional exploitation of a variety of resources. Missionaries have consistently played major roles in this process of contacting and pacifying native peoples in order to pave the way for industrial operations. Intuitive reasoning should have recognized centuries earlier that these cultures only existed because they had managed to develop a sustainable way of life in relation to their available resource base. Their continued existence as intact cultures heavily depends upon having ecosystems with conditions similar to the times when they were evolving (Swing 2011).

"Indigenous people are not the poor we must care for. They are the sages we must listen to." Father Augusto Zampini

While considering the globalized thought processes associated with environmental concerns, we should look to the major religions as potential allies for the purpose of gaining access to the masses. Although both insiders and outsiders might initially have doubts about how this might work, their enormous memberships and extensive geographic distributions present unusual opportunities. At 
least $75 \%$ of the world population claims to be adherents of widespread, popular religions which include creation stories and one or more creators. If believers have any reverence for their creator, then they should have some respect for the products of divine creation, thereby logically making them the greatest possible proponents of conservation and sustainability.

"While I know myself as a creation of God, I am also obligated to realize and remember that everyone else and everything else are also God's creation." Maya Angelou

"This is one of the greatest challenges of our time: to convert ourselves to a type of development that knows how to respect creation." Pope Francis

Most religions and traditions shun greed and the accumulation of wealth, but in the modern world, there is a paradoxical and entrenched admiration for wealth as well as rampant desire to constantly acquire material possessions. As a result, the combination of charisma and the overt flaunting of money have garnered the attention of the masses in many regions. Populist ideology, combined with the intentional manipulation of voters, as well as the authoritarian sowing of mistrust toward science, scientists and the press, represents a serious threat to Gaia and to ourselves. The scientific community has a duty to overcome these challenges. With our proven intellectual potential to solve problems, we should reasonably base refreshed hope in the timelessly optimistic words of Brazilian explorer Cândido Rondon.

"I believe... that Science, Art, and Industry will transform the Earth into Paradise, for all men, without distinction of races, beliefs, nations: banished the specters of war, of misery, of disease."

\section{FROM HERE, WHERE?}

The way forward must begin with the recognition that the serious global challenges we face are primarily a product of our own behavior. Although some behaviors are essentially hardwired, a huge part of our repertoire of behaviors is learned and thereby, malleable. Every day, hundreds to thousands of our words and deeds are filtered as acceptable or unacceptable by the cultures in which we live. Because we are highly social organisms, each one of us goes through life learning how to fit in, regularly making adjustments all along the way, primarily by imitating the behaviors of our elders and our peers. Ultimately, the way we think as well as the way we act are products of cultural standards. In the positive sense, these societal norms are constantly applied to reward and encourage certain attitudes and behaviors, or in the negative sense, to openly reject inappropriate or detrimental behaviors through personal interactions or the vote. As responsible world citizens, we all have a duty not only to live sustainably, but to pass along the underlying messages to others. The decisive question now is whether environmental risks can be incorporated as cultural pressures that, in turn, serve to modify the way we all think and act in relation to nature and planetary health.

To overcome the mountain of difficulties we have imposed upon ourselves, we must incorporate a few crucial ideas and multi-pronged remediation strategies if any semblance of modern civilization is to carry on. Rational answers exist; the will to act must be consequent. Any one of the following suggestions is a good place to start; any combination will certainly contribute more. Alternatives founded in ignorance portend an absolutely grim destiny for humankind.

1) Take the population explosion seriously enough to do something about it. To attain a fully equilibrated level of sustainability, we must not only slow the rate of increase in the short term, but also work toward an overall decrease in the total number of human beings for the long term.

Economists will not like an integral side effect of population reduction: that the number of 
producers, vendors and consumers cannot realistically increase forever. They and governments alike have no choice but to accept that human population expansion and all the concomitant expropriation of resources simply cannot continue in any functional sense along the trend line established during the last few decades.

Optimists, desperately seeking a silver lining perhaps, suggest that having more people means having more answers, by summing more creativity for problem solving. One must ask, however, if the total mass of creativity gained can possibly outweigh the ever mounting impacts and challenges. Do innovation and technology have a chance in this race if world powers and charismatic figures willingly choose to ignore scientific revelations or if political leaders simply do not understand the need for youngsters to be trained in science in the first place? Is this all for naught if the ruling class would actually prefer to keep the masses ignorant and easily manipulated instead of recognizing the overwhelming need for all minds to comprehend basic scientific principles and logical arguments?

A ray of hope does exist as a mathematical corollary of a growing population. According to global age pyramids, about $45 \%$ of the world population (Population Pyramid 2017) is under the age of 30 , meaning that they have most of a half century left to live - which should translate to a serious incentive to do something about the future. Although altruistic comments of leaving the planet in better conditions for our offspring abound, we have never really acted in a manner that might ensure that outcome in relation to natural resources and the environment. By and large, politicians across the planet have been older men with profound economic incentives to cling to the past and the systems that put them in powerful positions.
This fact has almost always guaranteed a broad disconnect between those in power and the issues of the day. The deeper significance is that political stances are typically outdated by decades, at least. Centuries ago, such a discrepancy may not have mattered so much, but recent technological advances have accentuated the generation gap dramatically turning it into an inconceivable and unjust chasm. Almost $40 \%$ of all people are between 20 and 40 years of age, meaning that young citizens can, en masse, vote to stop being relegated to living under the yoke of antiquated policies. In particular, first- and second-time voters can make their voices heard more than ever before to change situations to benefit their own futures. This bit of knowledge should readily convert the traditionally indifferent hoards into direct beneficiaries of decisions they make for their own world, given their own perspectives instead of having to wait for the wheels of government to grind along at a snail's (decrepit old man's) pace. As discerning voters, the masses must be well informed and capable of seeing beyond charisma and social media abuses. Candidates must demonstrate qualifications pertinent to the positions they seek. Politicians can no longer be allowed the escape phrase, "I'm not a scientist, but..." unless they show willingness to consult scientists before acting.

2) Recognize that we do not, and cannot, live alone on this planet. We need other species for reasons that extend from basic physiology and metabolism to any sense of physical or psychological wellbeing. For some highly simplistic examples, think of green plants producing oxygen and nutriment or bacteria sequestering toxins. Remember that part of prison is separation from nature, its colors, its panoramas, its sounds, its vitality, its diversity, its exuberance, etc. Other species also need 
space, tangible resources and non-toxic environments to exist and to thrive. As insect populations crash across the globe, every terrestrial ecosystem will essentially become non-functional. As we eliminate thousands to millions of species, it is impossible to reasonably believe that the network of life can or will go on providing our species with all the necessities of our own existence. Nature can only be generous to humans in the measure that we allow it to function.

3) Curtail carbon footprints (fossil fuel extraction/ combustion/consumption) at every level. Work toward the concept of living and consuming on a more local/regional scale rather than being part of the global demand for products that are only available from great distances. Stop transporting unnecessary goods across thousands, or even hundreds, of kilometers. Use more efficient transportation for the products that are indeed necessary. For example, use traditional highway transportation less and modern rail more. Push toward alternative energy.

4) Diminish production, usage and release of toxic chemicals drastically. As long as industry produces massive amounts of poisons, unintended impacts will always exist. Even the most careful contingency plans cannot entirely protect nature and humans from negative effects. Many industries have actively reduced risks, but none has eliminated them. At the legal level, we must move to apply the norms used for individuals to corporations and governments. For example, how can any coherent legal system require punishment of an individual who poisons his neighbors while ignoring the impacts of a powerful company that does precisely the same thing, but under the guise of some "greater good" that results from jobs and cash flow? Developing a legacy that extends the mentality of "thou shalt not kill" beyond individuals and society to the integrity of nature as a whole would benefit everyone and everything.

5) Notice that human health is environmental health. When we poison nature, we poison ourselves. Endless examples (cancers, respiratory ailments, reproductive challenges, etc.) cannot rationally continue to be dismissed.

6) Make concerted efforts to move away from traditional meat consumption. Although it is not imperative to have everyone convert immediately to vegetarianism, expanding plant-based diets would go far to approach a sustainable relationship with our resource bases. The consumption of wild-caught animals in particular, including many fisheries resources, has to be re-thought and minimized. Also, mentalities associated with industrialized animal husbandry must include much broader considerations.

7) Recycle and reuse as many plastic products as possible. Not only minimize the consumption of single-use plastics, but also minimize the production of these items. Recognize that plastics on the landscape and in our oceans not only represent a horrific eyesore but also cause extreme economic losses due to deadly entanglement of fauna. Additionally, many plastics emanate compounds deleterious to the reproduction of all biota, including ourselves and species we wish to consume. We are essentially giving contraceptives to all of nature while ignorantly hoping that everything can miraculously continue to reproduce.

8) Take advantage of existing organizational structures and passions. The majority of people across the planet claim affiliation to religions that involve one or more creators. Scientists and conservationists should reach out to religious leaders and seek respect for all of creation through high esteem for the creator(s). Nearly all cosmologies encompass a basic set 
of guidelines that have long served to orient adherents in regards to respect for others as well as life itself. Many of these lessons remain valid for people and our relationship to nature.

9) Knowledgeable individuals must be willing to participate as activists despite personal sacrifices. Once upon a time, science provoked admiration and specialists were justifiably sought out for their perspectives. That they represent informed sources with years of dedication to the analysis of particular topics has not changed. Scientific and educational communities must work together to regain this historical standing with the average citizen. Those individuals who arrogantly believe they know as much as leading scientists upon reading a website blog must be exposed to reality. As unattractive as it may sound to many professionals in science, true progress may necessitate direct involvement in politics. "One of the penalties for refusing to participate in politics is being governed by your inferiors." Plato

10) Educators must make science both relevant and accessible, effectively removing popular perceptions of exclusivity or frivolity. When the masses are kept in the dark by their own ignorance, the predictable result is an invitation for manipulation and corruption. The masses enjoy modern conveniences but tend to ignore the positive connections between science and its multitudinous contributions in medicine, communications, computing, transportation, energy production, construction, etc. Appreciation for applied science must be made contagious.

\section{CONCLUSIONS}

Opportunism, which is part of all species, is particularly keen in humans. This one characteristic has allowed us, has driven us, to selfishly commandeer vast portions of planetary resources for ourselves in a very short time frame with little regard for other species or for our own future. The pandemic contagion of materialist mentalities has set the stage for rampant unsustainable abuse of nature. While our numbers were small, we had the luxury of not caring very much about our impacts, but with population projections reaching astronomical proportions in the near future, historical lessons of apparently endless abundance must be unlearned so as to provide an aperture for reaching a rational relationship with our finite resource base. Intentionally ignoring warnings related to the interface between environmental health and human health forebodes a most risky scenario for coming decades. All hopes for a healthy environment as well as the very continuity of the human race depend immediately and ultimately upon much greater awareness and proactive dedication. Many interpret this to mean that the purest form of altruism is being called for in order to reach such a balance. In reality, it is actually deep-seated selfishness in relation to our own wellbeing that has the most potential to save us and what we recognize as civilization into the distant future. Looking out for our own best interests in the long run will certainly require a new and distinct kind of vision. This vision must extend far beyond short-term personal economic desires; it must conquer our myopic drive for instantaneous financial payoffs. This vision cannot be driven by cash flow but rather must be driven by thirst for scientific information and understanding in order to lead the way to realistic solutions. This vision must allow us to see that humans are a dependent part of nature and that nature does not, cannot, simply serve the role of subservient and passive facilitator of human life. This vision obligates us to comprehend human wellbeing entirely within the sphere of nature's wellbeing. In the end, this vision demands that we recognize the importance of functioning ecosystems in the integrated existence and happiness of all humankind. 


\section{REFERENCES}

ALCORN J. 2010. Indigenous People and Conservation. MacArthur Foundation Conservation White Paper Series, $49 \mathrm{p}$.

BAR-ON YM, PHILLIPS R AND MILO R. 2018. The biomass distribution on Earth. PNAS 115(25): 6506-6511.

CARSON RL. 1962. Silent Spring. Houghton Mifflin, NY, $368 \mathrm{p}$.

DIAMOND J. 1997. Guns, Germs and Steel; the Fates of Human Societies. Norton, NY, 480 p.

DIAMOND J. 2005. Collapse: How Societies Choose to Fail or Succeed. Penguin, NY, 575 p.

EHRLICH PR. 1968. The Population Bomb. Buccaneer Books, NY, $201 \mathrm{p}$.

GAUSE GF. 1934. The Struggle for Existence. Williams and Wilkins, Baltimore, $186 \mathrm{p}$

HARDIN G. 1968. The Tragedy of the Commons. Science 162(3859): 1243-1248.

KOLBERT E. 2014. The Sixth Extinction: An Unnatural History. Holt. NY, 319 p.

MALTHUS TR. 1798. An Essay on the Principle of Population. Johnson, London.
NOAA - NATIONAL OCEANIC AND ATMOSPHERIC ADMINISTRATION. 2019. What is a dead zone? https:// oceanservice.noaa.gov/facts/deadzone.html, Accessed 21 June 2018.

POPULATION PYRAMID. 2017. Population Pyramids of the World from 1950 to 2100 . https://www.populationpyramid. net/world/2017/, Accessed 10 May 2019.

SWING K. 2011. Endangered cultures need protection too. Nature 476: 283.

SWING K. 2014. Evolution in relation to environmental impacts and extreme species loss. In: Trueba G (Ed), Why does evolution matter? Cambridge Scholars Publishing, p. 77-86.

SWING K, DAVIDOV V AND SCHWARTZ B. 2012. Oil developmental on traditional lands of indigenous peoples; coinciding perceptions on two continents. J Developing Societies 28(2): 257-280.

WEBER M. 1905. The Protestant Ethic and "The Spirit of Capitalism”. Translated by Stephen Kalberg 2002, Roxbury Publishing Company.

WILSON EO. 2016. Half-Earth: Our planet's fight for life. Liveright/WW Norton, NY. 272 p. 